\title{
Dental fractures: types, causes, and treatment
}

\author{
Samar A. Bamofleh ${ }^{1 *}$, Alanoud F. Alotaibi ${ }^{2}$, Aidel A. Alshahrani ${ }^{3}$, Shoroug M. Alahmadi ${ }^{4}$, \\ Abdulaziz I. AlHumaidan', Sarah A. Abomelha ${ }^{6}$, Walaa A. Alkheshail ${ }^{7}$, \\ Rayyanah N. Almuhaydib ${ }^{7}$, Roaa M. Zafer ${ }^{8}$, Khloud M. Alkahtani ${ }^{9}$, Bashayer T. Albeladi ${ }^{10}$
}

\author{
${ }^{1}$ North Jeddah Specialist Dental Center, King Abdullah Medical Complex, Jeddah, Saudi Arabia \\ ${ }^{2}$ College of Dentistry, Riyadh Elm University, Riyadh, Saudi Arabia \\ ${ }^{3}$ Department of Restorative Dentistry, Medical Administration at Presidency of State Security, Riyadh, Saudi Arabia \\ ${ }^{4}$ General Dentist, Lamasat Al-Noor Clinics Complex, Medina, Saudi Arabia \\ ${ }^{5}$ Operation \& Maintenance Clinic, King Salman Naval Support Base, Riyadh, Saudi Arabia \\ ${ }^{6}$ General Dentist, Presidency of State Security, Riyadh, Saudi Arabia \\ ${ }^{7}$ General Dentist, Ministry of Health, Riyadh, Saudi Arabia \\ ${ }^{8}$ General Dentist, Almuzahmiah General Hospital, Riyadh, Saudi Arabia \\ ${ }^{9}$ General Dentist, Zahrat Al-Farabi Dental and Orthodontic Company, Riyadh, Saudi Arabia \\ ${ }^{10}$ General Dentist, Smile Team Dental Clinic, Al Ahsa, Saudi Arabia
}

Received: 23 December 2021

Accepted: 29 December 2021

\section{*Correspondence:}

Dr. Samar A. Bamofleh,

E-mail: samarabamofleh@gmail.com

Copyright: (C) the author(s), publisher and licensee Medip Academy. This is an open-access article distributed under the terms of the Creative Commons Attribution Non-Commercial License, which permits unrestricted non-commercial use, distribution, and reproduction in any medium, provided the original work is properly cited.

\begin{abstract}
Studies indicate that the management of dental fractures might be challenging because many cases present with minor, hard-to-discover traumas, requiring extensive evaluation and diagnostic procedures. Accordingly, adequate management can only be achieved by establishing a proper diagnosis, drawing an adequate treatment plan, and conducting regular follow-up appointments. We have discussed the different causes, types, and treatments of dental fractures. The commonest causes include impaction by trauma, whether direct or indirect. Many traumatic events were reported in the literature, and age and carious lesions are important factors to consider. Many types of dental fractures were also reported in the literature, including root fractures, crown root fractures, enamel-dentin fractures with and without pulp exposure or crown fractures, enamel infractions, and fractures. Other types include avulsion, intrusion, extrusion, lateral luxation, concussion or subluxation, splinting, and alveolar segment fractures. The treatment should be integrated based on the fracture type, and adequate follow-up should be established to achieve the best predictive outcomes.
\end{abstract}

Keywords: Dental fractures, Management, Evaluation, Etiology, Causes, Types, Classification

\section{INTRODUCTION}

Traumatic dental injuries are common, particularly among younger adults and children. Estimates indicate that around $5 \%$ of dental fractures are in these age groups. ${ }^{1,2}$ Studies indicate that the management of dental fractures might be challenging because many cases present with minor, hardto-discover traumas, requiring extensive evaluation and diagnostic procedures. $^{3} \quad$ Accordingly, adequate management can only be achieved by establishing a proper diagnosis, drawing an adequate treatment plan, and conducting regular follow-up appointments.

The front teeth of the upper jaw are the most commonly reported with traumatic fractures. This might be attributed to their position in the oral cavity and susceptibility to different traumatic events. Different causes have been proposed in the literature for traumatic fractures, including 
physical violence, traffic accidents, and sports activities. ${ }^{4}$ Different dental fractures can be found based on the extent and severity of injury and type of trauma. The treatment of these types is significantly based on the type of these lesions and the extent of the injury. The present literature review will discuss the causes and types of dental fractures and the proper treatment setup based on each type.

\section{METHODS}

This literature review is based on an extensive literature search in Medline, Cochrane, and EMBASE databases on which was performed 03 December 2021 using the medical subject headings $(\mathrm{MeSH})$ or a combination of all possible related terms, according to the database. To avoid missing poetential studies, a further manual search for papers was done through Google Scholar, while the reference lists of the initially included papers. Studies discussing clinical patterns, causes, and treatment of torus palatinus were screened for useful information, with no limitations posed on date, language, age of participants, or publication type.

\section{DISCUSSION}

\section{Types}

Based on patients' presentation and clinical evaluation, dental fractures can be classified into various types, including root fractures, crown root fractures, enameldentin fractures with and without pulp exposure or crown fractures, enamel infractions, and fractures. Avulsion, intrusion, extrusion, lateral luxation, concussion or subluxation, splinting, alveolar segment fractures, and concomitant fractures (affecting surrounding structures, including mandible, maxilla, and other facial structures) are other reported types of dental fractures that were discussed in the literature. It should be noted that enamel infractions are usually asymptomatic, and patients often present with microcracks that can only be discovered by transillumination. ${ }^{5,6}$ On the other hand, enamel fractures might be associated with and without pulp and dentin exposure based on the severity of the fracture and associated crown complications. In another context, crown-root fractures are apical and might extend to the pulp and impact the cementoenamel junction. Evidence indicates that these fractures that an apical extent is usually difficult to visualize the extent of fracture are usually below the gingival margin. Moreover, evidence indicates that the relevant fracture fragments are mobile and can be detected. Accordingly, patients might suffer from abnormal sensitivity to pressure and percussion. It is also recommended to conduct an occlusal X-ray imaging, a parallel periapical radiograph, and extra two longitudinal and transverse images. ${ }^{7,8}$ A cone-beam computed tomography (CT) scan might also help detect these lesions and decide the best treatment option. Finally, evidence shows that root fractures can be oblique, horizontal, or both and might impact cementum, pulp, or dentin. Various clinical findings can be detected on such occasions, including mobile or displaced crown fragments, tenderness on percussion, and gingival sulcus-related bleeding. A permanent or temporal neural injury might also be associated with these events. Accordingly, pulp tests can be initially negative, and further evaluation might be needed. The extension and location of fracture can be determined by conducting a radiographic examination. ${ }^{9,10}$ Other radiographic studies are also recommended, similar to the recommendations with crown fractures. Soft tissue lesions can also be associated with some cases. A missing tooth fragment might be the underlying etiology for these lesions in these cases. Therefore, they should be located and adequately managed. ${ }^{11,12}$

\section{Causes}

Various studies in the literature were published to indicate the causes of dental fractures. The main cause includes the application of a direct or indirect impact. The severity and extent of damage are also determined by many factors, including surrounding tissue response, shape energy, and direction of an impacting object. ${ }^{13}$ The commonest cause of traumatic dental fractures is falling, usually reported in around two-thirds of the cases. Physical violence, motor vehicle accidents, cycling accidents, and sporting injuries are other common causes of dental fractures. ${ }^{13-15}$ Age is an important factor to be considered when assessing the cause of dental trauma or fractures. For instance, it has been shown that dental fractures are more common among teenagers owing to sports and mong young adults (21-25 years old) owing to violence. Studies also show that the commonest cause of dental trauma is falls and collisions during primary dentition. ${ }^{13}$ It should also be noted that many predisposing factors have been reported in the literature that might facilitate the cause and occurrence of dental trauma and fractures. For instance, the presence of caries can remarkably cause fractures even with minor traumas. Traumatic injuries to the upper incisors are also common among patients with lip incompetence or increased overjet. ${ }^{16}$ Other predisposing factors were adequately discussed elsewhere in the literature. ${ }^{17,18}$

\section{Treatment}

Amid starting the specific dental treatment, it has been suggested that the application of cold packs to the site of injury might decrease the intensity of soft tissue swelling and pain. However, many cases with traumatic dental injuries are associated with the development of soft tissue injuries leading to lacerations, hematoma, and pain, which might further complicate these cases. The treatment of traumatic dental injuries differs based on the type of injury, and we will discuss them in this pattern. For instance, repositioning the crown fragments should be the first treatment approach for cases with root fractures. ${ }^{12,19} \mathrm{~A}$ radiological assessment is essential to ensure adequate repositioning. Besides, it has been reported that root canal treatment is not recommended during the emergency setting. Crown fragments should not also be removed in cases when the cervical fractures can heal. Using passive and flexible splints is also applicable in stabilizing mobile 
segments, which should be done for four weeks in apical and mid-third fractures and four months in cervical fractures. Adequate follow-up should then be conducted at 4 and 6-8 weeks, 6 , and 12 months, and annually for $\geq 5$ years. $^{12}$

Studies show that most cases with enamel infarction do not usually require any dental treatment. However, it should be noted that when there are extensive cracks, sealing and etching with bonding resin are recommended to intervene against the development of discoloration and secondary bacterial infections. On the other hand, treatment is different for enamel fractures and enamel-dentin fractures with uncomplicated crown fractures. For enamel fractures, various steps are encouraged to restore the tooth's continuity and normal functions. ${ }^{11,13}$

These include smoothing the edges of the tooth based on the extension of lesions and the availability of fragments. It might also be applied to tooth fragment reattachment and restoration with resin composite. Moreover, it has been recommended to conduct follow-up studies, including radiological and clinical evaluation of the treated teeth, after two months from conducting the treatment followed by another setting after one year. Such practice is recommended to assess the efficacy of treatment (restoration state) and the presence of secondary complications, including the development of an immature tooth (due to lack of root development), apical periodontitis, and pulp necrosis.

On the other hand, the management of uncomplicated enamel-dentin fractures is remarkably different. It has been recommended that a bonding agent and glass ionomer or composite resin be used to protect the exposed dentin. Evidence also indicates that some cases might present with dentin exposure in the proximal pulp, which might be observed as pink in color. However, no bleeding is usually associated. Managing these cases can be adequately done using a lining material (as calcium hydroxide), which might then be covered by another material (including glass ionomer). ${ }^{11}$ Fragment reattachment should also be considered when the conditions are suitable. However, it should be noted that this segment should be soaked in a saline solution or water for 20 minutes before conducting the procedure to maintain adequate tissue hydration. Besides, other procedures can also be conducted in such settings. These include ceramic restoration, wax-up, composite resin restoration, and direct resin composite restoration.

The treatment of enamel-dentin fractures with complicated crown fractures or pulp exposure differs. Evidence indicates that these events should be managed by restoring the tooth structure and managing the exposed pulp. In general, it has been recommended that a conservative approach manage these cases because when a pulp-capping material is usually used, evidence indicates the potential of the affected tooth to develop a dentinal ridge following pulp exposure. Accordingly, it has been questionable whether to conduct partial pulpotomy or pulp capping. Many factors can answer this question. For instance, it has been reported that it is significantly dependant on the presence of simultaneous luxation injuries, stage of root development, tooth age, the state of pulp amid the injury, and the severity and time of exposure. Authors also indicate that a short exposure period is the only indication for pulp capping. This is because longer durations might be associated with an increased risk of irreversible inflammatory reactions and bacterial invasion. ${ }^{20}$ Besides, it has been shown that clinicians should not measure a diameter $>1.5 \mathrm{~mm}$ for the exposed area. Finally, the process of pulp healing might be associated with various factors, which might also indicate the adequacy of pulp capping. These include younger teeth, the absence of associated luxation injuries, the presence of immature teeth with open apices, and healthy pulp status amid the trauma. ${ }^{11,21}$

When pulp capping has been contraindicated, evidence shows that the treatment of choice is partial pulpotomy, which should be done for young teeth with open apices. These events are usually encountered in cases of an extensive diameter of exposure and prolonged duration since the trauma occurred. A previous study reported that pulp amputation should be conducted to the extent where the tissue is believed to be healthy (i.e. $2 \mathrm{~mm}$ below the exposed area). ${ }^{22}$

Conducting partial pulpotomy is recommended in these cases because it enhances the tooth's vitality for long-term periods. Therefore, it can be considered a suitable longterm treatment alternative when capping is contraindicated. Finally, root canal treatment is recommended in these settings and adequate restoration. It should also be noted that a clinical decision is necessary based on these cases' clinical and radiological evaluation. For instance, clinicians should be able to decide whether ceramic restoration, fragment reattachment, or indirect or freehand resin composite restoration is suitable. Radiological and clinical follow-up settings should be conducted after adequately managing these cases at 6-8 weeks, 3,6 , and 12 months.

The first step in managing crown root fractures is removing tooth fragments to assess pulp involvement and fracture extent better. This is usually done to adequately expose the fracture margins and allow for moist and bleeding control, enabling attending clinicians to control plaque formation in the affected patients adequately. After the fragment has been retrieved, a composite resin or glass ionomer can be furtherly used to cover the remaining dentin tissues when the pulp is not exposed.

However, it should be noted that it has been recommended that whenever the fracture is apical to the cementoenamel junction, this treatment should only be considered conservative. $^{23}$ 
Evidence also indicates the suitability of other various treatment modalities. These include extraction, autotransplantation, intentional replantation with and without root rotation, vital root submergence, forced surgical extrusion, orthodontic extrusion with and without gingivoplasty, and osteotomy or gingivectomy. Regular check-ups should also be conducted by radiological and clinical evaluation every 1 and 6-8 weeks, 3, 6, and 12 months, and annually for $\geq 5$ years. ${ }^{11,12}$

\section{CONCLUSION}

The commonest causes include impaction by trauma, whether direct or indirect. Many traumatic events were reported in the literature, and age and carious lesions are important factors to consider. Many types of dental fractures were also reported in the literature, including root fractures, crown root fractures, enamel-dentin fractures with and without pulp exposure or crown fractures, enamel infractions, and fractures. Other types include avulsion, intrusion, extrusion, lateral luxation, concussion or subluxation, splinting, and alveolar segment fractures. The treatment should be integrated based on the fracture type, and adequate follow-up should be established to achieve the best predictive outcomes.

\section{Funding: No funding sources Conflict of interest: None declared \\ Ethical approval: Not required}

\section{REFERENCES}

1. Petersson EE, Andersson L, Sörensen S. Traumatic oral vs non-oral injuries. Swedish Dent J. 1997;21(12):55-68.

2. Juneja P, Kulkarni S, Raje S. Prevalence of traumatic dental injuries and their relation with predisposing factors among 8-15 years old school children of Indore city, India. Clujul Med. (1957). 2018;91(3):328-35.

3. Diangelis AJ, Andreasen JO, Ebeleseder KA, et al. Guidelines for the Management of Traumatic Dental Injuries: 1. Fractures and Luxations of Permanent Teeth. Pediatric Dentistry. 2017;39(6):401-11.

4. Bratteberg $\mathrm{M}$, Thelen DS, Klock KS, Bårdsen A. Traumatic dental injuries-Prevalence and severity among 16-year-old pupils in western Norway. Dent Traumatol. 2018;34(3):144-50.

5. Son PT, Reda A, Viet DC. Exchange transfusion in the management of critical pertussis in young infants: a case series. Vox Sang. 2021;116(9):976-82.

6. Pham TS, Reda A, Ngan Nguyen TT, Ng SJ, Huan VT, Viet DC, Huy NT. Blood exchange transfusion in viral hepatitis in a small infant: a case report. Transfus Apher Sci. 2020;59(6):102907.

7. Nguyen TM, Huan VT, Reda A, Morsy S, Nam Giang HT, Tri VD, et al. Clinical features and outcomes of neonatal dengue at the Children's Hospital 1, Ho Chi Minh, Vietnam. J Clin Virol. 2021;138:104758.
8. Thieu H, Bach Dat B, Nam NH, Reda A, Duc NT, Alshareef A, et al. Antibiotic resistance of Helicobacter pylori infection in a children's hospital in Vietnam: prevalence and associated factors. Minerva Med. 2020;111(5):498-501.

9. El-Qushayri AE, Dahy A, Reda A, Mahmoud MA, Mageed SA, Kamel AMA, Ghozy S. A closer look at the high burden of psychiatric disorders among healthcare workers in Egypt during the COVID-19 pandemic. Epidemiol Health. 2021;43:e2021045.

10. El-Qushayri AE, Ghozy S, Reda A, Kamel AMA, Abbas AS, Dmytriw AA. The impact of Parkinson's disease on manifestations and outcomes of Covid-19 patients: A systematic review and meta-analysis. Rev Med Virol. 2021;e2278.

11. Olsburgh S, Jacoby T, Krejci I. Crown fractures in the permanent dentition: pulpal and restorative considerations. Dent Traumatol. 2002;18(3):103-15.

12. Bourguignon C, Cohenca N, Lauridsen E, Flores MT, O'Connell AC, Day PF, et al. International Association of Dental Traumatology guidelines for the management of traumatic dental injuries: 1 . Fractures and luxations. Dent Traumatol. 2020;36(4):314-30.

13. Zaleckiene V, Peciuliene V, Brukiene V, Drukteinis S. Traumatic dental injuries: etiology, prevalence and possible outcomes. Stomatologija. 2014;16(1):7-14.

14. Faus-Damiá M, Alegre-Domingo T, Faus-Matoses I, Faus-Matoses V, Faus-Llácer VJ. Traumatic dental injuries among schoolchildren in Valencia, Spain. Medicina oral, patologia oral y cirugia bucal. 2011;16(2):292-5.

15. Hecova H, Tzigkounakis V, Merglova V, Netolicky J. A retrospective study of 889 injured permanent teeth. Dent Traumatol. 2010;26(6):466-75.

16. Artun J, Behbehani F, Al-Jame B, Kerosuo H. Incisor trauma in an adolescent Arab population: prevalence, severity, and occlusal risk factors. Am J Orthodont Dentofac Orthoped. 2005;128(3):347-52.

17. Jones LC. Dental Trauma. Oral Maxillofac Surg Clin North Am. 2020;32(4):631-8.

18. Santos Filho PC, Quagliatto PS, Simamoto PC, Soares CJ. Dental trauma: restorative procedures using composite resin and mouthguards for prevention. J Contemp Dent Pract. 2007;8(6):89-95.

19. Love RM. Bacterial penetration of the root canal of intact incisor teeth after a simulated traumatic injury. Endodont Dent Traumatol. 1996;12(6):289-93.

20. Cox CF, Bergenholtz G, Heys DR, Syed SA, Fitzgerald M, Heys RJ. Pulp capping of dental pulp mechanically exposed to oral microflora: a 1-2 year observation of wound healing in the monkey. J Oral Pathol. 1985;14(2):156-68.

21. Baume LJ, Holz J. Long term clinical assessment of direct pulp capping. Int Dent J. 1981;31(4):251-60.

22. Cvek M. A clinical report on partial pulpotomy and capping with calcium hydroxide in permanent incisors with complicated crown fracture. J Endodont. 1978;4(8):232-7. 
23. Yu CY, Abbott PV. Responses of the pulp, periradicular and soft tissues following trauma to the permanent teeth. Austral Dent J. 2016;61:39-58.
Cite this article as: Bamofleh SA, Alotaibi AF, Alshahrani AA, Alahmadi SM, AlHumaidan AI, Abomelha SA, et al. Dental fractures: types, causes, and treatment. Int J Community Med Public Health 2022;9:995-9. 